\title{
Technology-Mediated Education Caused by the COVID-19 Pandemic Reflected in Students and Teachers' Stories Via the Application of Storytelling Techniques
}

\begin{abstract}
The article focuses on stories, revealing personal experiences related to the technology-mediated education caused by the COVID-19 pandemic and storytelling as a tool in qualitative research. Stories and storytelling may play an important part in qualitative research through presenting a unique, subjective view, which may contribute to the universal perspective. The transition to online teaching has been related to the pandemic, that constitutes a traumatic experience, generating further difficult experiences of an individual nature, which need to be told and shared. That is why, the research through storytelling in the context of the transition to online reality, caused by the pandemic seems to be adequate. Stories as natural phenomena to the human psyche and everyday existence may provide an interesting insight into online teaching, which might have been lost in the limitations of other research tools.

Keywords: technology-mediated education, online education, stories, storytelling, koan
\end{abstract}

"A story constitutes then, a fifth element"1

Olga Tokarczuk

\section{Introduction}

You are in this place. In this large, spacious room, where you sit behind the massive, mahogany desk. You may feel its surface: it is polished, smooth, warm and cool at the same time. So are the desks that are visible in front of you: elegant and smooth occuping the place.

You may see them, placed in harmonious rows. There are chairs behind them. As empty as they are, for the time being, you may feel their impatience to be filled with these creatures that would listen to you. At last, they come and you may start.

1 “Opowieść jest więc piątym żywiołem” (Tokarczuk, 2020, pp. 23-24) [translation mine].

Anna Pełczyńska, Filologia Angielska, Instytut Społeczno-Prawny, Państwowa Wyższa Szkoła Zawodowa im. Angelusa Silesiusa, ul. Zamkowa 4, 58-300 Wałbrzych, apelczynska@pwsz.com.pl, https://orcid.org/ 0000-0002-9108-0418 
And you talk and talk and talk until you are tired and close your eyes for a moment. To open them for a new reality. There are no desks anymore nor students listening to you. There is only one chair: yours. And there is only one place: home. Yours. There is no spaciousness in front of you. You feel like there are mirrors everywhere, like in "halls of mirrors where/in every place we look we see our stare" (Jennings, 1986, pp. 24-26).

The mirrors in which you and your words are reflected are no longer the mirror of human eyes, but the smooth surface of a computer screen.

You talk to the computer as if it were a human being able to reach out to other human beings.

At the same time, you are alone with yourself.

And you talk and talk and talk until you are tired and close your eyes for a moment.

Is talking to the computer part of being a human?

When teaching through a computer, do we teach ourselves?

Does teaching through a computer make me more human? Or humane?

The above text represents the attempt of writing a koan of my own in order to start the discussion of the phenomenon of technology-mediated education. Unfortunately, the idea of starting an academic text with a koan is not mine, which is to be explained further in this paper.

The koan is defined as:

a surprising or paradoxical word or phrase, taken from an anecdote, that is used as an object of meditation in traditions descended from Chinese Chan Buddhism, like Japanese Zen. Contemplating these words is part of the training given by a teacher to help a Buddhist student to awaken (Editors, 2021).

As it was stated before, it had not been my idea to start an academic text with a koan. I was inspired by the book Cosmological Koans: A Journey to the Heart of Physical Reality by Anthony Aguirre (2019)2. The construction of the book is unique in that every scientific phenomenon is preceded by a koan related to the topic (Aguirre, 2019, 2021).

Koan is also important in the context of this paper, because of its meanings: one of them is a story (Editors, 2021).

A story occupies a meaningful place in the context of technology-mediated education, especially because of the fact that it has been forced by the COVID-19 pandemic.

2 The Author of the paper became acquainted with the book in Polish version Kosmologiczne Koany. Podróż do serca rzeczywistości fizycznej, translated into Polish by Tomasz Lanczewski 
It cannot be denied that the COVID-19 pandemic has been a traumatic experience. The experience has been categorized as a "collective trauma" (Bologna, 2021). The phenomenon is defined below:

Individual trauma is a traumatic event that happens to a person, whereas collective trauma happens to not just a small group of people but society," said Dan Reidenberg, a mental health expert and executive director of Suicide Awareness Voices of Education. "Collective trauma changes history and memory for many. It changes the way we process and see not only the trauma that was experienced but what we do with our memory of it as we move forward (Bologna, 2021).

Trauma needs to be healed and one of the tools to deal with traumatic experiences is storytelling. Telling stories constitutes a part of psychological therapy:

Telling the trauma story to a supportive therapist is one of the key components of Cognitive Behavioral Therapy (CBT), which is one of the most effective treatments for post-traumatic stress disorder (PTSD). I recently explored the latest findings on PTSD treatment research with psychologist Dr Mark Powers, Director of Trauma Research at Baylor Scott and White Health. As we discussed, effective CBT typically doesn't require an intensive examination of the survivor's beliefs and evidence for those beliefs, as is often done in CBT for other conditions. Instead, insights about the truth of what happened emerge just through talking about what happened and what it means (Gillihan, 2021).

The above stated psychological benefits of telling stories and also the very immediate association of trauma caused by the pandemic has led to the assumption that the application of storytelling as an idea and a qualitative research tool is a natural solution in academic discussions related to technology-mediated education.

This paper consists of two parts. The first part is devoted to the theoretical foundations related to stories and storytelling. They are necessary to present the empirical part that consists of the collected stories written by students. There is also a koan (rudimentary one) written by me, as the person representing the teacher's point of view.

\section{Theoretical part: storytelling}

Storytelling is a complex phenomenon that embraces many layers of meaning, reflected in the variety of its definitions. The definitions seem to be very similar yet every one of them presents a different facet of this diamond (story), described by Tokarczuk (2020) as "the fifth element". That is the reason for presenting several of the selected definitional approaches to story and storytelling.

\subsection{Storytelling: definition}

Storytelling is defined in a variety of ways. That is why the selected definitions of the phenomenon are presented in this section of the paper. 


\subsubsection{The fundamental aspects of storytelling}

The most concise definition of storytelling is given by Serrat (2017): "Storytelling is the vivid description of ideas, beliefs, personal experiences, and life-lessons through stories or narratives that evoke powerful emotions and insights" (p. 839). There are several aspects mentioned:

- vividness;

- a system of ideas and convictions, expectations;

- events in personal life;

- elements of affective domain (experiences);

- elements of sageness, sapience (pp. 839-840).

It is vital to remember that storytelling operates not only within the boundaries of the intellect. It originates and functions within an affective domain, being created and creating through emotions). The most fundamental aspect of creative writing, which is the source of the written stories is mystery (Dąbała, 2004, p. 87)

\subsubsection{Mystery as a source of storytelling}

There are two elements that constitute creative writing, a story-making tool, and these are mystery and suspense (Dąbała, 2004). However, mystery is the essential element. A story may not have suspense, but it has to possess the mystery. What is more, there is more than one kind of mystery:

Creative writing points to the existence of basic varieties of mystery, even though they may not be referred to directly. In the centre of interest here is primarily the mystery of the other person, the mystery of God or the mystery of one's own self (Dąbała, 2012, p. 64).

All of these varieties of mystery may be found also in stories told to each other every day. It may be due to the fact that narration is found at the very core of human existence and human nature: "Narration is naturally rooted in various scholarly disciplines but also in life itself" (Dąbała, 2012, p. 25). The innateness of stories, of narrative formats originated from the term "homo narratus".

\subsubsection{Homo narratus}

The essence of the homo narratus concept may be found in the claim "Humans are the Stories They Tell about Themselves" (Richardson, 2013). Stories are not only the products of creative writing, they are also part of everyday life. They are told all the time, to family, friends, strangers, sometimes to pets and plants. What is interesting, they are also told to ourselves. The stories in our heads would be the most influential in shaping human lives and characters.

There are elements necessary for the story to be told. These are narrative transactional formats, which consists of the following elements: canonical steady state, precipitating event, restoration and coda marking the end (Dautenhahn, 2002, 
p. 256). Dautenhahn (2002, pp. 248-249) discusses Narrative Intelligence Hypothesis (NIH), which is based on a set of reasons, given below:

1) Individualized societies are a necessary (but possibly not sufficient) 'substrate' for the evolution of narratives. In such societies, members know each other personally.

2) The specific narrative format of such transactions serves an important communicative function among primates and has possibly evolved independently in other groups of species that live in individualized societies. Narrative capacities co-evolved in order to cope with increasingly complex dynamics.

3) The evolution of communication in terms of narrative language (storytelling) was an important factor in human evolution that has shaped the evolution of human cognition, societies and human culture. The use of language in a narrative format provided an efficient means of 'social grooming' that maintains group coherence.

4) Pre-verbal transactions in narrative format bootstrap a child's development of social competence and social understanding.

5) Human cultures which are fundamentally 'narrative' in nature provide an environment that young human primates are immersed in and facilitate not only the development of a child into a skilled storyteller and communicator but also the development of an autobiographical self.

The set of arguments listed above indicate the vital role of storytelling in contributing to the development of human cognitive capacities, human societies as well as to individual development. This might form a place of narrative intelligence within the theory of MI theory - the theory of Multiple Intelligences (described by Davis, Christodoulou, Seider, \& Gardner, 2011, pp. 485-502).

\subsubsection{The story, context and performance}

A story reaches beyond its characters, plot, atmosphere, which is conceptualized within pragmatics and sociolinguistics as well as branches of linguistics (Stapleton \& Wilson 2017). Apart from all of these qualities there exist external factors, which, via their paradoxical nature, may turn out to be internal. The elements are the teller and the telling (Stapleton \& Wilson 2017, pp. 61-63). The teller is the person who tells the story, whereas the telling "is the situated act of story-telling or narration, including its interactional and social features" (p. 62). There is also the third element, the tale, which is the story fabric, together with the timeline, the characters, and the chain of events (pp. 61-63). The last factor, the quintessential one, is heavily influenced by the two external ones. The story is modified by the teller, filtered through their subjective selves. Additionally, it is modified, sometimes even recreated by the telling.

Each act of telling contributes to the reshaping of a story. That is why, it is a context-bound, fluid, ever-changing entity, which makes it a perfect tool for 
reflecting reality, the phenomenon of the same qualities. The story influences and is influenced by the teller and the telling, which are both the parts of a tale as well as storytelling tools.

\subsection{Storytelling: functions}

As there are several definitional aspects of stories and storytelling, there also exist several functions of the phenomena, through which they may also be defined.

\subsubsection{Communicative function of storytelling}

Storytelling is defined in the context of human communication as the essence of being human, which is reflected in the expression homo narratus (Richardson, 2013). The functions of stories and narratives are discussed below:

And stories seem to be the most efficient method to communicate about the world, others and self, as they are loaded with social information. If the social theory of the development of language is valid, the narrative is the mortar of human society and the catalyst of culture. Stories brought us together and made us human, which is why Kerstin Dautenhahn, biologist and professor of computer science, calls us Homo narratus, the storytelling hominid (Richardson, 2013).

Stories are not only fiction-makers but also information-providers. The perception of stories as the fabric and the tools of entertainment has obscured their communicative role of passing information.

Dautenhahn (2002) also uses the term "communicative function":

With a few exceptions (Read \& Miller, 1995), most discussions on the 'narrative mind' have neglected the evolutionary origins of narrative. Research on narrative focuses almost exclusively on language in humans (see, e.g., Turner, 1996). Similarly, the narrative is often conceived of as a (sophisticated) art form, rather than serving a primarily communicative function[....]. Human narrative capacities are not unique and there is an evolutionary continuity that links human narratives to transactional narrative formats in social interactions among animals. Also, from a developmental point of view, we argue that narrative capacities develop from the pre-verbal, narrative, transactional formats that children get engaged in with their parents and peers. Instead of focusing on differences between humans and other animals, we point out similarities and evolutionary, shared histories of primates with specific regard to the origins and the transactional format of narratives (pp. 248-249).

The ability to tell stories is not human-specific. It may also shape animal reality. One may draw the conclusion that stories are not only a fundamental part of civilization but also a part of nature (with animals using narrative formats).

The story is not only art. It is a tool that serves many practical purposes: passing information, forming relationships, strengthening bonds, creating societies. A culture may be defined as a shared inventory of stories, especially myths:

Myths are stories that are deep and enduring. Myths represent the shared belief of people within a society (or in our case, members within an organization). Myths can address the past, the 
present, or the future by telling the listener how things have been (Levy, 1994), why we behave a certain way (Belk \& Tumbat, 2005), how to behave (Whelan \& O'Gorman, 2007), or even what happens if we fail to act in a certain way (Livingston, 1965). Stories take on mythic qualities when they represent a shared vision, are carefully retold, and passed to the next generation. Over the years, the authors have heard many mythic stories when they visited organizations (Kendall, J. \& Kendall, K., 2012, p. 168).

\subsubsection{Research function: storytelling as a research tool}

Storytelling, through its communicative function, may be used as a tool in the qualitative approach in conducting research, as is illustrated by the study:

In this paper we explore early IS research using stories and story fragments, reveal what we learn from observing how researchers in other disciplines use storytelling, and adopt the tenets of the social construction of technology (SCOT) theory as a useful lens for understanding organizational members' creation of shared meaning through IS stories. Realizing that organizational storytelling today is much like the telling of myths, we propose that researchers need to appreciate the story as a whole. We also assert that researchers need to identify the purpose, the telling, and the order in which the story is told. Our goal is to inspire IS researchers to realize the depth and richness found in organizational stories and to appreciate and use stories in their own work (Kendall, J. \& Kendall, K., 2012, pp. 161-162)

\subsubsection{Storytelling as a pedagogical tool}

Storytelling may also be applied in language learning:

Storytelling is one of the oldest forms of human communication, and much has been said in the literature about its effectiveness as a pedagogical tool in the development of language skills in first (L1) language, and also in a foreign or second language (L2), regardless of a learners' age or background (e.g., Isbell, Sobol, Lindauer, \& Lowrance, 2004; Cameron, 2001). Furthermore, storytelling is even claimed to be more effective in language teaching than traditional teaching materials, such as textbooks. Indeed, studies generally believe that the effectiveness of storytelling relies on the fact that it is fun, engaging and highly memorable, raising learners' interest in listening to stories (Lucarevschi, 2016, pp. 24-25).

\section{Empirical part: the application of storytelling in conducting research into technology-mediated education in the COVID-19 pandemic}

In this part of the paper, storytelling is applied within all of its functions mentioned in 1.2. First of all, it has been used as a tool in qualitative methodological approach, then as a pedagogical tool and, finally, in its communicative function. Obviously, there is no linear placement of all the functions; they overlap and permeate each other, forming a specific mechanism.

\subsection{The goal of the research: research questions}

The goal of this study was to collect stories, revealing personal experiences related to the technology-mediated education caused by the COVID-19 pandemic. The following research questions guided the studies: 
1) How may the storytelling technique be applied in the context of online education caused by COVID-19 pandemics?

2) What are the stories, related to online education, caused by the COVID-19 pandemic, that the students would like to share?

3) How may the storytelling device be enhanced to elicit more personal experiences and insights in the possibly most natural way?

\subsection{Methodology}

Stories and storytelling require an individual and open approach, which are the characteristic features of qualitative research (Wilczyńska \& Michońska-Stadnik, 2010 , p. 140). Hence, the research approach is qualitative, the research tool is storytelling and text analysis. In this study, storytelling is also considered as a form of inquiry, a special type of in-depth interview.

\subsection{Participants}

The participants of the research represented the students of the second and third years of philology. Only $20 \%$ decided to take part in the first task of the research project and $11 \%$ decided to take part in the second task. The smaller amount of participants in the case of the second task might be justified with the writing of their diplomas, as none of the students of the third year wrote the story for the second part of the research.

\subsection{Procedure}

In order to conduct this study five procedures were implemented. They are presented in the table below:

Table 1. The procedures implemented in the study

\begin{tabular}{|c|c|}
\hline $\begin{array}{l}\text { The number } \\
\text { of the procedure }\end{array}$ & The description \\
\hline 1 & $\begin{array}{l}\text { A discussion of the technology-mediated education in the context of the } \\
\text { COVID-19 pandemic. }\end{array}$ \\
\hline 2 & The presentation of the role of stories in trauma. \\
\hline 3 & $\begin{array}{l}\text { The presentation of the first task (TASK 1): writing stories after the following } \\
\text { instruction: } \\
\text { The outbreak of the pandemic caused by COVID-19 has brought a transition } \\
\text { from face-to-face contact in an educational context to technology-mediated } \\
\text { education, mainly online education. } \\
\text { In March 2020, the students and academics met online to continue the } \\
\text { teaching and learning process. } \\
\text { Do you remember your first thought concerning your online classes and } \\
\text { lectures? What was it? How has it evolved? } \\
\text { How did the transition to technology-mediated education change your life? } \\
\text { How did it change your view on education, on life, on yourself? }\end{array}$ \\
\hline
\end{tabular}


Technology-Mediated Education Caused by the COVID-19 Pandemic Reflected in Students... 27

\begin{tabular}{|c|c|}
\hline $\begin{array}{c}\text { The number } \\
\text { of the procedure }\end{array}$ & The description \\
\hline 3 & $\begin{array}{c}\text { What is the most unique/happiest/ saddest/ most outraging, etc. experience } \\
\text { concerning technology-mediated education caused by the COVID-19 } \\
\text { pandemic? }\end{array}$ \\
& $\begin{array}{c}\text { First sentences to inspire: The 50 Best First Sentences in Fiction (gawker.com) } \\
\text { Introducing the second task (TASK 2), with the first sentence given by the } \\
\text { researcher: }\end{array}$ \\
& $\begin{array}{c}\text { 1. Write a story, related to education online, that starts with the sentence: } \\
\text { I will never forget this online class (lecture) when .......... } \\
\text { 2. Put your story aside for a day or two. } \\
\text { 3. Read your story and describe its tone. }\end{array}$ \\
\hline
\end{tabular}

\subsection{Results}

As a result of the conducted research, eight stories for the first task (TASK 1) and five stories for the second one (TASK 2) were delivered.

\subsection{The analysis of the results}

There is a difference between the first set of stories and the second one. For the sake of this study, they may be labelled as stories-task1 (ST1) and the second "wave", stories related to task 2 (ST2). The difference consists of two aspects: opinion-giving and emotional.

In the case of ST1, the opinion-giving aspect dominates over the emotional. One may have an impression that some students misunderstood the task of writing narrative forms related to online classes and lectures with producing an opinion about them, which may be illustrated by the example: "At first, the teachers seemed quite confused and the material they provided was heavier to learn. The weaker transmission of the material consisted of many things, including a poor internet connection, a poorly prepared platform for voice conferences, low involvement on the part of students and general irritation with the existing conditions. With time, many lecturers adopted their new style and with each lecture, the classes became more and more similar to those of the university. I think that the summer break allowed us all to refine the system in which we work until today because this academic year remote learning looks much better than in the previous one" (S3 ST1) ${ }^{3}$.

3 Students, research participants, had numbers assigned to them. It was mainly the researcher's decision; the students usually did not mind being mentioning by their names. However, the application of numbers for the students, together with the number of texts seem to contribute to the transparency 
It may be due to the fact that students are accustomed to assessing classes, lectures and academic teachers through questionnaires. The second reason is that the instruction for TASK 1 was open and general, without many guidance points.

In ST2, the emotional aspect was more visible, whereas there were less opinions. It may be due to the fact that the instructions were clearer and guided by first sentence.

The first sentence is vital to the story. It is labelled as a narrative hook (Turco, 1991, p. 41). There are many Internet sources, giving advice on how to write a well-constructed first sentence ${ }^{4}$. The first sentence is helpful in writing the rest of the story, as is illustrated by this study.

As for the dichotomy of positive and negative aspects of online education, the negative one predominates. Most of the students were unsatisfied with the necessity of classes and lectures online. Factors like isolation, lockdown, lack of personal contact with peers, the company of household members, and not always being agreeable, have been presented: "After three months it started to get to me that the isolation is not the best for me. Working with children via the internet made me burnt out of my passion for teaching and studying online became torture" (S1 ST1); "Sitting at home with parents whom I do not have a good connection with, only going out on walks with my dog, dealing with my grandfather's death, and now my father battling with covid and taking care of my mother and grandma, took a big toll on me. School was also not a big help in all of this" (S5 ST1).

Qualitative research enables unexpected results. On of them is an unusual insight into the problem with online education: "I have the impression, at least on my example, that after this pandemic I will lose some aspects that make up my identity. Mainly, in this case, I refer to the external image. Because of the fact that I am sitting at home during an online lesson with the camera turned off, I am unable to express myself through my appearance or style of dress. Suddenly I changed all my favourite pants into tracksuits and leggings. It is a bit depressing. As a whole, I believe this is some kind of test. I have the impression that this situation may be more difficult for children attending primary school" (S6 ST1).

The concept of self-expression through clothes usually does not appear in the context of education. Yet, it may be a vital aspect, especially in language education, language being a complex phenomenon that requires body language for communication. Apart from this, language and art (which is connected with selfexpression via external image) may have a lot in common.

of the research project. S1 ST1 translates as: Student number 1 who is a participant of task 1 of this research project. One person is mentioned by name as he specifically asked for it.

4 How to Write a Great First Sentence, with 22 Examples (annerallen.com); How to Write a Winning First Sentence (convinceandconvert.com); The 50 Best First Sentences in Fiction (gawker.com). 
The ST2 stories were more personal, as was stated before. The most personal story deals with the death of a relative: "I will never forget this online class (lecture) when I got a phone call from my mum [...] dad is dead. I couldn't believe it" (S2 ST2). This particular story is written with short, monomorphemic lexical items, active voice and direct speech predominates. All of these elements reflect this dramatic situation, one of the traumas of the COVID-19 pandemic that students faced.

Finally, there are two stories, for TASK 1 and TASK 2, written by the same person, whom these empirical studies revealed to be artistically talented and who also made a self-discovery. The S4 texts are presented, both for TASK 1 and TASK 2: "Imagine a daunted, sad and desireless person, sitting in front of the computer at home, trying to study things. Yes, that's me.

Ever since March 2020, I felt stressed, depressed, frightened of tomorrow. At first, I thought that the pandemic won't last for long and, oh boy, was I wrong. I was very sceptical of the idea that teaching will work in a remote format, in fact, I still am... The technology was not prepared for this amount of people connecting online. Constant connection issues meant an unpleasant experience during lectures. To put it simply, it was terrible, for at least a couple of weeks.

Transitioning to remote learning wasn't a tough thing to manage, at least for me. I know people that still don't know how to operate a computer, but oh well... Since I play a lot of video games in my free time, jumping over to remote education was as simple as apple pie. But that transition took a large toll on my social life. I love meeting people on the school premises and its still possible mind you, but it lacks something that makes these encounters fun, enjoyable.

Since the start of the pandemic, my life hasn't changed much. I still have contact with my family and friends. One difference would be the way how I think about the future of mine. Now, I feel anxious of what the future will bring, and that's really daunting, because you can't think straight at times. It's barely impossible to have thoughts about hundreds of different things... overthinking just makes things worse, believe me, I know.

The unique thing about the pandemic and the tech-oriented form of education is that you don't have to move from home to get things done. Everything is being done remotely, user to user, without the need to suffocate yourself with these awful masks and that's cheering... especially after the train wreck that 2020 has been.

Anyway, that's the reality of living during a pandemic, my reality. Thank you for reading" (S4 ST1).

"I'll never forget this online class when I was asked to present my hobby to other students. Obviously, I prepared a lengthy, interactive presentation featuring elements of my hobby, photography. I did a bit of research, found engaging facts that are connected to the given subject and chose some good and interesting photographs of my own, as well as some old-school ones. 
The presentation was prepared and ready to be shown after a few days.

Day-zero was upon me. The amount of stress, that was overflowing my body throughout the morning, was tough to handle. Heavy sweating, among other things, annoyed me the most. Little did I realize that I've already shown my hobby to the whole class. Honestly, these were the shortest 30 minutes of my life.

To my surprise, the reception of everything that I've presented was simply amazing. Some people were genuinely interested in my hobby and asked various kinds of questions that I was more than pleased to answer!

That was the day to remember. The day when I broke the barrier of anxiety and stress during speech" (S4 ST2).

As is illustrated by the texts above, the stories are interesting, and the discovery is that the writer does not experience anxiety and stress when performing in public anymore. It is one of the rare examples of the benefits of online education. Another one is illustrated by my own story as the representative story of an academic teacher.

\section{The koan and the further research perspectives}

The story mentioned above is my (attempt at) a koan that begins this paper. One of the functions of koans is to change the perspective in order to change the mode of thinking. Usually, a koan ends with one question, but here several questions are presented:

Is talking to the computer a part of being a human?

When teaching through a computer, do we teach ourselves?

Does teaching through a computer make us more human? Or humane?

The questions have been partly answered in this paper. There is still a lot to discover within the realms of these questions. That is why they constitute a field for further research.

\section{References}

Aguirre, A. (2019). Cosmological Koans: A Journey to the Heart of Physical Reality. New York: W. W. Norton \& Company.

Aguirre, A. (2021). Kosmologiczne Koany. Podróż do serca rzeczywistości fizycznej. Kraków: Copernicus Center Press.

Bologna, C. (2021, April 4). How Is Collective Trauma Different From Individual Trauma? [Blog]. Retrieved April 5, 2021, from https://www.huffpost.com/entry/collective-trauma-meaning_1_ $606 \mathrm{cc} 3 \mathrm{cfc} 5 \mathrm{~b} 6 \mathrm{c} 70 \mathrm{eccaa} 99 \mathrm{~cd}$.

Dautenhahn, K. (2002). The Origins of Narrative: In Search of the Transactional Format of Narratives in Humans and Other Social Animals. International Journal of Cognition and Technology, 1(1), 97-123. Retrieved April 2, 2021, from http:/www.al-edu.com/wp-content/uploads/2014/05/Kerstin-Dautenhahn-Narrative-Intelligence-2001.pdf. 
Davis, K., Christodoulou J., Seider S., \& Gardner, H. (2011). The Theory of Multiple Intelligences. Cambridge Handbook of Intelligence (pp. 485-503). Retrieved May 3, 2021, from https:// www.researchgate.net/publication/317388610 The Theory of Multiple Intelligences.

Dąbała, J. (2004). Tajemnica i suspens. Wokół głównych problemów creative writing. Lublin: Wydawnictwo Uniwersytetu Marii Curie-Skłodowskiej.

Dąbała, J. (2012). Mystery and Suspense in Creative Writing. Münster: LIT Verlag.

Editors, the (2021). What Is a Koan? The Buddhist Review Tricycle. Buddhism for Beginners. What Is a Koan? from Buddhism for Beginners - Tricycle. Retrieved May, 5, 2021, from https:// tricycle.org/magazine/what-is-a-koan/.

Gillihan, S. J. (2021). The Healing Power of Telling Your Trauma Story. Psychology Today. Retrieved May 5, 2021, from https://www.psychologytoday.com/us/blog/think-act-be/201903/ the-healing-power-telling-your-trauma-story.

Jennings, E. (1986). Collected Poems, Manchester: Carcanet Press.

Kendall, J., \& Kendall, K. (2012). Storytelling as a qualitative method for is research: heralding the heroic and echoing the mythic. Australasian Journal of Information Systems, 17(2), 168-169.

Lucarevschi, C. R. (2016). The role of storytelling in language learning: A literature review. WPLCWorking Papers of the Linguistics Circle of the University of Victoria, 26(1), 24-44. Retrieved April 30, 2021, from https://journals.uvic.ca/index.php/WPLC/article/view/15309.

Richardson, R. B. (2013). Narrative Madness: Humans are the Stories They Tell about Themselves. [Blog]. Retrieved April 5, 2021, from http://ronaldbrichardson.com/metafiction/narrativemadness-humans-are-the-stories-they-tell-about-themselves/.

Serrat, G. (2017). Storytelling. Knowledge Solutions, 839-842. Singapore: Springer. DOI: 10.1007/978-981-10-0983-9_91.

Stapleton, K., \& Wilson, J. (2017). Telling the story: Meaning making in a community narrative. Science Direct. Journal of Pragmatics, 108, (60-80). DOI: 10.1016/j.pragma.2016.11.003.

Tokarczuk, O. (2020). Czuły Narrator. Kraków: Wydawnictwo Literackie.

Turco, L. (1999). The Book of Literary Terms: The Genres of Fiction, Drama, Nonfiction, Literary Terms, and Scholarship. Hannover, London: University Press of New England.

Wilczyńska, W., \& Michońska-Stadnik, A. (2010). Metodologia badań w glottodydaktyce. Wprowadzenie. Kraków: Avalon. 